\title{
Outcomes following thoracotomy or thoracoscopic vascular ring division in children and young adults
}

\author{
Melissa A. Herrin, BA, ${ }^{\mathrm{a}}$ David Zurakowski, PhD, ${ }^{\mathrm{b}}$ Francis Fynn-Thompson, MD, ${ }^{\mathrm{a}}$ \\ Christopher W. Baird, MD, ${ }^{\mathrm{a}}$ Pedro J. del Nido, MD, ${ }^{\mathrm{a}}$ and Sitaram M. Emani, MD ${ }^{\mathrm{a}}$
}

\section{ABSTRACT}

Objective: To determine the short- and intermediate-term outcomes following vascular ring division by video-assisted thoracoscopic (VATS) or thoracotomy approach.

Methods: This study is a retrospective review of patients with double aortic arch or right aortic arch with aberrant left subclavian artery and left ligamentum (RAA with LSCA/LL) who underwent division via left thoracotomy or VATS approach at a single institution. Outcome measures included operation duration (OR time), hospital length of stay (LOS), postoperative complications, and freedom from reintervention.

Results: A total of 200 patients underwent vascular ring division by VATS $(\mathrm{n}=115)$ or thoracotomy $(\mathrm{n}=85)$. Of 200 patients, $125(56 \%)$ displayed respiratory symptoms at presentation, $29(11 \%)$ displayed digestive tract symptoms, and $41(32 \%)$ displayed both. Median follow-up was 2.1 years (interquartile range: 1 month to 7.1 years). Overall cohort mortality was $1(0.5 \%)$ of 200 at 11 years after surgery. Fifteen $(7.5 \%)$ experienced immediate postoperative complications. At follow-up visit within 1 month after surgery, 92 (74\%) of 125 patients reported improvement in symptoms. Freedom from reintervention was $96 \%$ and $90 \%$ at 5 years and 10 years, respectively. Among patients with RAA with LSCA/LL $(\mathrm{n}=113)$, VATS was associated with shorter LOS compared with thoracotomy ( 1.2 vs 3.4 days; $P<.001)$, but rates of complications were not significantly different ( $9 \%$ vs $4 \%, P=.68)$.

Conclusions: Vascular ring division by either thoracotomy or VATS can be performed with low rates of complication and need for reintervention. Compared with thoracotomy, VATS is associated with shorter operative duration and hospital LOS among patients with RAA with LSCA/LL. (J Thorac Cardiovasc Surg 2017;154:607-15)

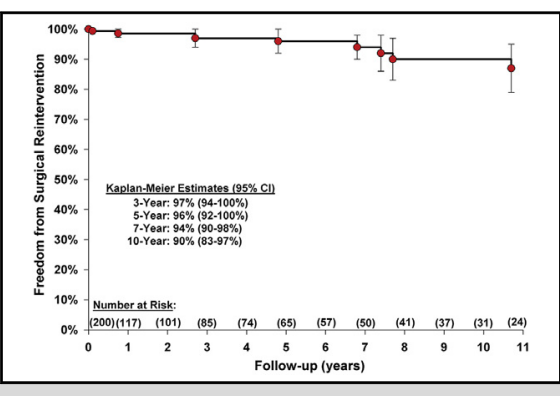

Freedom from reintervention in 200 patients undergoing vascular ring division 1991 to 2015.

\section{Central Message}

Vascular ring division by either thoracotomy or VATS can be performed with low rates of complication and need for reintervention.

\section{Perspective}

Our study describes a single institutional experience and found that division of vascular rings is safe and effective. Furthermore, VATS is a feasible alternative approach for surgical management of vascular rings. In patients with right aortic arch with aberrant left subclavian artery and left ligamentum, VATS is associated with shorter hospital length of stay compared with thoracotomy.

See Editorial Commentary page 616
Complete vascular rings are vascular anomalies of the aortic arch that encircle and may cause compression of the trachea and esophagus leading to respiratory or gastroesophageal symptoms. Although there are many forms of vascular rings, double aortic arch (DAA) and right aortic arch

From the ${ }^{\mathrm{a} D e p a r t m e n t s ~ o f ~ C a r d i a c ~ S u r g e r y ~ a n d ~}{ }^{\mathrm{b}}$ Anesthesia and Surgery, Boston Children's Hospital, Harvard Medical School, Boston, Mass.

Read at the 96th Annual Meeting of The American Association for Thoracic Surgery, May 14-18, 2016, Baltimore, Maryland.

Received for publication May 19, 2016; revisions received Dec 29, 2016; accepted for publication Jan 28, 2017; available ahead of print March 31, 2017.

Address for reprints: Sitaram M. Emani, MD, Department of Cardiac Surgery, Boston Children's Hospital, 300 Longwood Ave, Bader 273, Boston, MA 02115 (E-mail: Sitaram.Emani@cardio.chboston.org).

$0022-5223 / \$ 36.00$

Copyright (C) 2017 by The American Association for Thoracic Surgery http://dx.doi.org/10.1016/j.jtcvs.2017.01.058
(RAA) with aberrant left subclavian artery/left ligamentum (LSCA/LL) are the most common. Surgical division of the vascular ring, performed in symptomatic patients with significant airway compression, is effective, with excellent outcomes in most patients, including significant reduction and resolution of symptoms and low risk of morbidity and mortality. ${ }^{1-4} \quad$ Minimally invasive video-assisted

Scanning this $\mathrm{QR}$ code will take you to the article title page. To view the AATS 2016 Webcast, see the URL next to the video thumbnail. 


$$
\begin{aligned}
& \text { Abbreviations and Acronyms } \\
& \text { CT = computed tomography } \\
& \text { DAA double aortic arch } \\
& \text { EA }=\text { esophageal atresia } \\
& \mathrm{IQR}=\text { interquartile range } \\
& \text { LL = left ligamentum } \\
& \text { LOS } \quad=\text { length of stay } \\
& \text { LSCA = left subclavian artery } \\
& \text { MRI = magnetic resonance imaging } \\
& \text { OR = operating room } \\
& \text { OR time }=\text { operation duration } \\
& \text { PDA }=\text { patent ductus arteriosus } \\
& \text { RAA = right aortic arch } \\
& \text { TEF }=\text { tracheoesophageal fistula } \\
& \text { VATS }=\text { video-assisted thoracoscopic surgery }
\end{aligned}
$$

thoracoscopic surgical (VATS) techniques have been applied to division of vascular rings, enabled by availability of thoracoscopic instruments and high-resolution cameras, and has been shown to be feasible and safe for vascular ring division. ${ }^{5-7}$ Major disadvantages of VATS approach for vascular ring division include inability to reimplant the subclavian artery and possible increased risk of bleeding and other complications. Limited data are available regarding safety and efficacy of VATS approach for vascular ring division.

Single-institution series have been reported, but overall long-term freedom from intervention, including symptom resolution and follow-up evaluation, following VATS or thoracotomy remains incompletely characterized in this population. ${ }^{1,3,4,8}$ The primary objective of this study was to describe outcomes (complication rate, symptom relief, rate of reintervention) of surgical vascular ring division by either thoracotomy or VATS.

\section{PATIENTS AND METHODS}

This study is a retrospective review of patients treated at a single institution, Boston Children's Hospital, between January 1991 and December 2015. Patients who underwent division of a DAA or RAA with LSCA/ LL were identified and a retrospective review of medical records was performed. Patients were excluded according to the following criteria: other forms of vascular compression syndrome (including left pulmonary artery sling or innominate artery compression), weight $<3.2 \mathrm{~kg}$, undergoing concomitant cardiac surgery at vascular ring division, or utilization of sternotomy or right thoracotomy approach. Furthermore, patients were excluded if their medical records had significant missing data (operative reports, body weight). The study design and methods were approved by the Boston Children's Hospital Institutional Review Board.

Demographic, clinical, surgical, and follow-up data were collected on all patients. Demographic data included gender, age, and weight, vascular ring anatomy, concomitant congenital abnormalities, and presenting symptoms at time of surgery. Specific vascular ring anatomy was classified based on documented operative findings if it differed from findings on preoperative imaging. Objective measurements of the Kommerell diverticulum were not available for all patients with RAA with LSCA/LL; however, a diverticulum was generally defined if the diameter of the base was 1.5 times larger than diameter of left subclavian artery immediately distal to the diverticulum. Tracheal narrowing was determined based on qualitative or quantitative documentation in preoperative computed tomography (CT), magnetic resonance imaging (MRI), or bronchoscopy. Presenting symptoms were classified as respiratory or gastroesophageal in nature, or both, based on preoperative and operative clinical documentation.

Patients were classified as having undergone VATS versus thoracotomy using procedure description in operative notes. Those patients who required conversion from VATS to thoracotomy approach were recorded. Clinical follow-up time was calculated from date of surgery until date of the most recent documented clinical encounter in the medical record.

For VATS approach, 4 small skin incisions were placed in the periscapular position, with 3 of the 4 incisions being along the incision pathway for thoracotomy and the fourth incision placed in the subaxillary position. A 30- or 45-degree rigid scope mounted on an external retractor and connected to external monitor was used for visualization. A fan retractor was placed through a second port for lung retraction, whereas 2 ports were used for dissection and ring division. For thoracotomy approach, a serratus-sparing or latissimus/serratus-sparing posterolateral thoracotomy was performed.

We recorded outcomes in patients undergoing vascular ring division. Short- and medium-term outcome endpoints included operation length (OR time) defined by time into operating room $(\mathrm{OR})$ to time out of OR, hospital length of stay (LOS), postoperative complications, and need for surgical reintervention. Duration of operation and hospital LOS were collected from the clinical record. Postoperative complications were defined as conditions in the immediate postoperative period requiring significant intervention for pneumothorax, hemothorax, or chylothorax, such as chest tube placement or thoracic duct ligation. Postoperative complications also included documented paralysis or paresis of left vocal cord, suggesting laryngeal nerve injury, although systematic assessment of vocal cord function was not routinely performed in all patients. We defined reintervention as surgical manipulation of the aortic arch, division of residual band tissue, or tracheal surgery for persistent tracheal compression noted on follow-up imaging.

To investigate symptoms after vascular ring division by either VATS or thoracotomy approach, subgroups with early ( $<1$ month) clinical evaluation by cardiology following surgery and any follow-up $>6$ months were further analyzed. Acute symptom resolution was determined from documentation of the clinical visit in the early postoperative period. Among patients with follow-up more than 6 months after surgery date, the rate of persistent symptomatic airway abnormalities was determined by review of postoperative CT, MRI, laryngoscopy, and bronchoscopy.

Additionally, in a subgroup of patients with RAA with LSCA/LL, we compared duration of operation, hospital LOS, and rates of complications between patients undergoing VATS versus thoracotomy. Comparative analysis was limited to this subgroup as patients with this diagnosis were not excluded from either approach and were not significantly different in age and weight. On the other hand, patients with DAA were more likely to undergo thoracotomy due to presence of patent aortic arch.

Descriptive statistics were described as frequency (\%) for categorical variables and as median and interquartile range (IQR) for continuous variables. Freedom from reintervention was analyzed by longitudinal KaplanMeier methodology. When comparing demographic characteristics and outcomes in subgroups of the thoracotomy and VATS groups, we used $\chi^{2}$ or the Fisher exact test for categorical variables, as appropriate, or the Wilcoxon rank-sum test for continuous (non-normally distributed) variables. Analysis of covariance (ANCOVA) was used to compare OR time and hospital LOS between VATS and thoracotomy approaches in the subgroup of patients with RAA with LSCA/LL. In this same group, freedom from reintervention between VATS and thoracotomy was compared using Kaplan-Meier analysis with a log-rank test to compare the groups. Error 
bars around the Kaplan-Meier curves denote $95 \%$ confidence intervals determined by the Greenwood formula. ${ }^{9}$ Results were considered statistically significant for 2-tailed $P<.05$. All statistical analyses were conducted with IBM SPSS Statistics (version 23.0; IBM Corporation, Armonk, NY).

\section{RESULTS \\ Patient Characteristics}

A total of 200 patients met inclusion and exclusion criteria and were subsequently analyzed. Median followup for this cohort was 2.1 years (IQR: 1 month to 7.1 years). Table 1 summarizes baseline cohort data, including gender, age, weight, presenting symptoms, vascular ring anatomy, and prevalence of concomitant congenital cardiac abnormalities.

\section{Operative Characteristics}

A total of 115 patients underwent VATS and 85 underwent thoracotomy for division of complete vascular ring. Table 2 summarizes gender, age, weight, anatomy, and presenting symptoms for patients by surgical approach. Patients who underwent VATS had a median age of 2.7 years (IQR: $1.0-6.4$ ); those who underwent thoracotomy had a median age 0.9 years (IQR: $0.2-4.4$ ). Furthermore, patients who underwent VATS had a median weight of $14.2 \mathrm{~kg}$ (IQR: 8.7-24.0); patients who underwent open had a median weight $8.9 \mathrm{~kg}$ (IQR: 4.9-16.5). A greater proportion of patients with a diagnosis of RAA with LSCA/LL underwent VATS $(87 / 113,75 \%)$.

Of the 115 VATS cases, $63(55 \%)$ were performed between 1991 and 2005, whereas $52(45 \%)$ were performed since 2006. In comparison, among 85 thoracotomy cases, $35(41 \%)$ were performed between 1991 and 2005, whereas 50 cases (59\%) were performed between 2006 and 2015;

TABLE 1. Demographic, preoperative, and perioperative clinical characteristics of 200 patients undergoing vascular ring division 1991-2015

\begin{tabular}{lc}
\hline \multicolumn{1}{c}{ Characteristic } & $\mathbf{N}=\mathbf{2 0 0}$ \\
\hline Gender, male:female ratio & $109 / 91$ \\
Age, y, median (IQR) & $1.8(0.6-6.2)$ \\
Weight, kg, median (IQR) & $11.5(7-22)$ \\
Follow-up time, y, median (IQR) & $2.1(0.04-7.1)$ \\
Diagnosis, n (\%) & \\
RAA with LSCA/LL & $113(57)$ \\
DAA with patent arch & $55(27)$ \\
DAA with atretic arch & $32(16)$ \\
Cardiac abnormalities, n (\%) & $67(34)$ \\
Symptoms at presentation, n (\%) & \\
Respiratory & $111(56)$ \\
Gastroesophageal & $22(11)$ \\
Both & $63(32)$ \\
Asymptomatic & $4(2)$ \\
\hline$I Q R$, Interquartile range; $R A A$, right aortic arch; $L S C A$, left subclavian artery; $L L$, left \\
ligamentum; $D A A$, double aortic arch.
\end{tabular}

TABLE 2. Demographics, clinical characteristics, and outcomes in patients undergoing video-assisted thoracoscopic surgery and thoracotomy for vascular ring division

\begin{tabular}{|c|c|c|}
\hline Variable & $\begin{array}{c}\text { VATS } \\
\mathbf{n}=115\end{array}$ & $\begin{array}{c}\text { Thoracotomy } \\
\mathbf{n}=\mathbf{8 5}\end{array}$ \\
\hline Gender, male, $\mathrm{n}(\%)$ & $63(55)$ & $46(54)$ \\
\hline Age, y, median (IQR) & $2.7(1.0-6.4)$ & $0.9(0.2-4.4)$ \\
\hline Weight $(\mathrm{kg})$, median (IQR) & $14.2(8.7-24.0)$ & $8.9(4.9-16.5)$ \\
\hline \multicolumn{3}{|l|}{ Diagnosis, n (\%) } \\
\hline DAA with atretic arch & $24(21)$ & $8(9)$ \\
\hline DAA with patent arch & $4(3.5)$ & $51(60)$ \\
\hline RAA with LSCA/LL & $87(75)$ & $26(31)$ \\
\hline $\begin{array}{l}\text { Resection of Kommerell } \\
\text { diverticulum and reimplantation } \\
\text { of the left subclavian artery }\end{array}$ & $0 / 87$ & $2 / 26$ \\
\hline \multicolumn{3}{|l|}{ Symptoms at presentation, $\mathrm{n}(\%)$} \\
\hline Respiratory & $75(65)$ & $36(42)$ \\
\hline Gastroesophageal & $6(5)$ & $16(19)$ \\
\hline Both & $31(27)$ & $32(38)$ \\
\hline Asymptomatic & $3(2.6)$ & $1(1.1)$ \\
\hline Follow-up time, mo, median (IQR) & $26(0.3-85)$ & $26(0.7-85)$ \\
\hline OR time, h, median (IQR) & $3(2.4-3.6)$ & $3(2.7-3.8)$ \\
\hline Hospital LOS, days, median (IQR) & $1.3(1.1-2.2)$ & $3.4(2.5-6.2)$ \\
\hline Complications, n (\%) & $10(9)$ & $5(6)$ \\
\hline DAA with atretic arch & $1 / 24$ & $0 / 8$ \\
\hline DAA with patent arch & $1 / 4$ & $4 / 51$ \\
\hline RAA with LSCA/LL & $8 / 87$ & $1 / 26$ \\
\hline $\begin{array}{l}\text { Converted from VATS to open } \\
\text { thoracotomy, } \mathrm{n}(\% \text { of converted) }\end{array}$ & & 12 \\
\hline DAA with atretic arch & & $3(25)$ \\
\hline DAA with patent arch & & $5(42)$ \\
\hline RAA with LSCA/LL & & $4(33)$ \\
\hline Reintervention, $\mathrm{n}(\%)$ & $3(2.6)$ & $5(5.9)$ \\
\hline DAA with atretic arch & $1 / 24$ & $0 / 8$ \\
\hline DAA with patent arch & $0 / 4$ & $3 / 51$ \\
\hline RAA with LSCA/LL & $2 / 87$ & $2 / 26$ \\
\hline Time to reintervention, y, median (IQR) & $2.7(0.7-\mathrm{N} / \mathrm{A})$ & $6.8(2.4-9.2)$ \\
\hline
\end{tabular}

VATS, Video-assisted thoracoscopic surgery; $I Q R$, interquartile range; $D A A$, double aortic arch; $R A A$, right aortic arch; $L S C A$, left subclavian artery; $L L$, left ligamentum.

this slight imbalance did not reach statistical significance $(P=.078)$.

Among 127 patients who underwent attempted VATS vascular ring division, $12(9 \%)$ were converted from a VATS approach to thoracotomy (Table 2). The decision was made intraoperatively to convert to thoracotomy from VATS approach. Reasons for conversion included observation that a vessel previously classified as atretic was patent (patent ductus arteriosus [PDA], patent DAA), posterior aortic arch, inadequate deflation of lung, minor bleeding from the intercostal vein, minor bleeding from the diverticulum of Kommerell, dense pleural adhesions, and short length of atretic segment of double arch to be divided. Two patients underwent conversion for bleeding, but neither required perioperative blood transfusion. 


\section{Short- and Intermediate-Term Outcomes}

Fifteen patients $(7.5 \%)$ experienced postoperative complications, including 7 patients $(3.5 \%)$ with left vocal cord paresis (Table 2). Complications among thoracotomy patients included tracheostomy for severe respiratory distress immediately postoperatively, 1 pneumothorax requiring chest tube placement, 1 chylothorax requiring ligation of thoracic duct/lymphatic vessels, 1 wound dehiscence and required re-exploration, and 2 patients with vocal cord paresis. Complications among VATS patients included 4 chylothoraces requiring ligation of thoracic duct/ lymphatic vessels, 1 pneumothorax requiring chest tube placement, and 5 patients with documented left vocal cord paresis.

\section{Long-Term Outcomes}

One patient died $(0.5 \%) 11$ years after vascular ring division from end-stage renal disease related to congenital renal abnormalities. Eight patients (4\%) of the 200 who underwent vascular ring division required reintervention (Table 3). After vascular ring division, freedom from reintervention was $96 \%$ and $90 \%$ at 5 years and 10 years, respectively (Figure 1). All 8 patients returned to care presenting with recurrent respiratory symptoms, including stridor, increasing dyspnea with activity, and/or progressive cough. Indications for reintervention were a combination of symptoms and imaging demonstrating significant tracheal and/or esophageal compression. Procedures performed in reintervention surgeries included aortopexy, diverticulopexy, tracheopexy, and reimplantation of the subclavian (Table 3). At reintervention, in 3 patients, residual band tissue was discovered within the bed of ligamentum tissue. Division of this residual tissue resulted in relief of compression. Among the 91 patients with RAA and Kommerell diverticulum, 71 did not receive aortopexy, manipulation of the diverticulum, or reimplantation of the
LSCA. Among these 71 without diverticular intervention at the time of original surgery, 4 patients required reintervention.

Documented clinical follow-up beyond discharge was available in $160(80 \%)$ of 200 patients. Among 125 patients who had an early postoperative cardiology clinic evaluation within 1 month of discharge, $92(74 \%)$ were asymptomatic at the time of the visit. A total of 130 patients had documented clinical follow-up beyond 6 months, and 29 patients underwent follow-up diagnostic imaging for evaluation of persistent or recurrent symptoms, including CT, MRI, laryngoscopy, or bronchoscopy. Of the patients undergoing diagnostic imaging, $17(59 \%)$ were noted to have airway abnormalities. Where a comparison with preoperative imaging was possible $(\mathrm{n}=13), 10(77 \%)$ patients demonstrated improvement in airway compression compared with preoperative imaging.

\section{RAA With Aberrant Left Subclavian}

Among the 113 patients with a diagnosis of RAA with LSCA/LL, 91 (85\%) had a documented enlarged Kommerell diverticulum by preoperative imaging and/or operative note (Table 2). Two of these 91 patients underwent reimplantation of the LSCA during the initial surgery due to concerns of potential compression. In 1 patient, the diverticulum size was measured at $1.6 \mathrm{~cm}$ by $2 \mathrm{~cm}$ on MRI report or $0.1 \mathrm{~cm}^{2} / \mathrm{kg}$ body weight. Seventeen patients with diagnosis of RAA underwent aortopexy during the initial surgery, all of whom had a documented diverticulum of Kommerell.

Patients who underwent repair of RAA with LSCA/LL by VATS $(n=87)$ were compared with those undergoing thoracotomy $(\mathrm{n}=26)$ and were not significantly different in age (36 months; IQR $15-83$ vs 17 months; IQR: 8-90, $P=.14)$ and weight (14.9 kg; IQR: $10.2-24.7$ vs $9.2 \mathrm{~kg}$; IQR: 7.1-26.7, $P=.07$ ) (Table 4). Follow-up time was

TABLE 3. Characteristics and operative procedures of 8 patients requiring reintervention after vascular ring division

\begin{tabular}{|c|c|c|c|c|c|}
\hline & $\begin{array}{r}\text { Surgical } \\
\text { approach }\end{array}$ & $\begin{array}{c}\text { Vascular ring anatomy } \\
\text { (diagnosis) }\end{array}$ & $\begin{array}{c}\text { No. of } \\
\text { reintervention } \\
\text { surgeries } \\
\end{array}$ & $\begin{array}{l}\text { Time to } \\
\text { reintervention, } y\end{array}$ & Procedures performed \\
\hline 1 & Thoracotomy & RAA with LSCA and LL & 1 & 10.7 & Aortopexy \\
\hline 2 & VATS & DAA with atretic arch & 1 & 0.74 & Division of residual band tissue \\
\hline 3 & VATS & RAA with LSCA and LL & 1 & 7.4 & Diverticulopexy, division of residual band of tissue \\
\hline 4 & Thoracotomy & DAA with patent arches & 2 & $\begin{array}{l}\text { 1. } 7.7 \\
\text { 2. } 16.7\end{array}$ & $\begin{array}{l}\text { 1. Aortopexy, division of residual band tissue } \\
\text { 2. Aortopexy, tracheopexy }\end{array}$ \\
\hline 5 & Thoracotomy & DAA with patent arches & 2 & $\begin{array}{l}\text { 1. } 6.8 \\
\text { 2. } 7.9\end{array}$ & $\begin{array}{l}\text { 1. Aortopexy } \\
\text { 2. Aortopexy }\end{array}$ \\
\hline 6 & VATS & RAA with LSCA and LL & 1 & 2.7 & Aortopexy \\
\hline 7 & Thoracotomy & DAA with patent arches & 1 & 4.8 & Aortopexy and tracheopexy \\
\hline 8 & Thoracotomy & RAA with LSCA and LL & 1 & $4 \mathrm{~d}$ & $\begin{array}{l}\text { Aortopexy, reimplantation of left subclavian artery } \\
\text { into ascending aorta }\end{array}$ \\
\hline
\end{tabular}

RAA, Right aortic arch; $L S C A$, left subclavian artery; $L L$, left ligamentum; VATS, video-assisted thoracoscopic surgery; $D A A$, double aortic arch. 


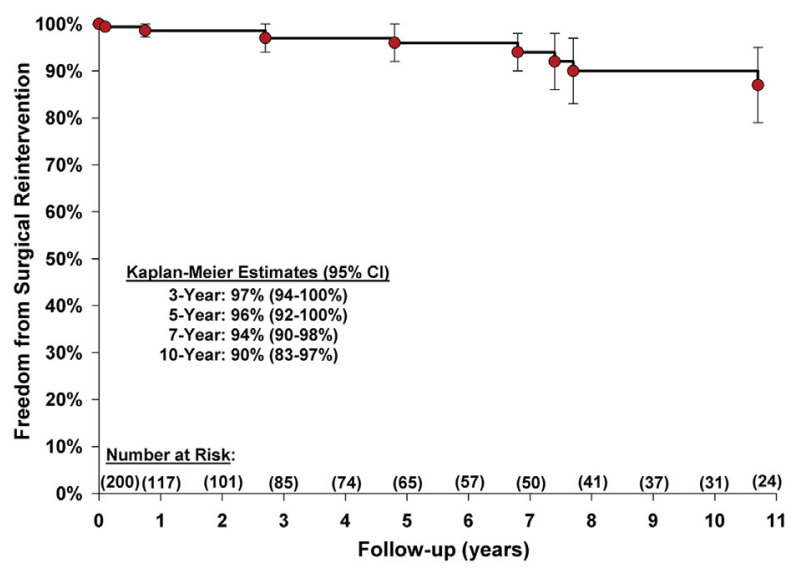

FIGURE 1. Kaplan-Meier curve of freedom from reintervention in 200 patients undergoing vascular ring division by video-assisted thoracoscopic surgery or thoracotomy 1991-2015.

similar between VATS (26 months [0.2-89]) compared with thoracotomy (27 [0.8-123], $P=.64)$. Among those patients for whom operation time was available $(n=65)$, OR time was slightly shorter among patients who underwent VATS (3.1 hours; IQR: 2.4-3.5) compared with thoracotomy (3.3; IQR: 3.0-4.0, $P<.05)$. Hospital LOS was significantly shorter among patients who underwent VATS compared with thoracotomy (1.2 days; IQR: $1.0-2.2$ vs 3.4 days; IQR: 2.3-4.2, $P<.001)$. ANCOVA indicates that after adjustment for age and weight at surgery, patients with RAA with LSCA/LL undergoing thoracotomy spent on average 40 minutes longer in the $\mathrm{OR}(P=.027)$ and 3 days longer in the hospital $(P=.012)$ compared with VATS. To account for any potential bias introduced from classifying converted cases under thoracotomy approach,

TABLE 4. Demographic characteristics and operative, short-, intermediate-, and long-term outcomes in patients with right aortic arch with aberrant left subclavian artery and left ligamentum who underwent video-assisted thoracoscopic surgery compared with thoracotomy

\begin{tabular}{|c|c|c|c|}
\hline Variable & $\begin{array}{l}\text { VATS } \\
\mathrm{n}=87\end{array}$ & $\begin{array}{c}\text { Thoracotomy } \\
\mathbf{n}=\mathbf{2 6}\end{array}$ & $P$ \\
\hline Age, mo, median (IQR) & $36(15-83)$ & $17(8-90)$ & .14 \\
\hline Weight, kg, median (IQR) & $14.9(10.2-24.7)$ & $9.2(7.1-26.7)$ & .07 \\
\hline $\begin{array}{l}\text { Follow-up time, mo, } \\
\text { median (IQR) }\end{array}$ & $26(0.2-89)$ & $27(0.8-123)$ & .64 \\
\hline OR time, $h$, median (IQR) & $3.1(2.4-3.5)$ & $3.3(3.0-4.0)$ & $.04 *$ \\
\hline $\begin{array}{l}\text { Hospital LOS, d, } \\
\text { median (IQR) }\end{array}$ & $1.2(1.0-2.2)$ & $3.4(2.3-4.2)$ & $<.001 *$ \\
\hline Complications, $\mathrm{n}(\%)$ & $8(9)$ & $1(4)$ & .68 \\
\hline Reintervention, n (\%) & $2(2)$ & $2(8)$ & .23 \\
\hline $\begin{array}{l}\text { Time to reintervention, } \\
\text { years, median (IQR) }\end{array}$ & $5.1(2.7-\mathrm{N} / \mathrm{A})$ & $3.4(2.3-4.2)$ & 1.00 \\
\hline
\end{tabular}

analyses were repeated after classifying converted cases as VATS or by excluding the patients from both groups, and differences between VATS and thoracotomy persisted. There was trend toward a higher rate of complications following VATS $(\mathrm{n}=8,9 \%)$ compared with thoracotomy ( $\mathrm{n}=1,4 \%$ ); however, this difference did not reach statistical significance $(P=.68)$. There was a lower rate of reinterventions in VATS $(\mathrm{n}=2,2 \%)$ compared with thoracotomy $(\mathrm{n}=2,8 \%$ ); however, this difference did not reach statistical significance in the Fisher exact test $(P=.23)$ or log-rank test $(P=.29)$ (Table 4$)$.

\section{DISCUSSION}

This study found that vascular ring division by either VATS or thoracotomy approach is safe and effective in patients undergoing surgery for DAA or RAA with LSCA/LL. Rates of complications, need for reintervention, and mortality were low with good symptom resolution, particularly in the early postoperative period.

The rate and nature of the complications and reinterventions in this series were similar when compared with previous vascular ring series, including vocal cord paresis. $3,4,10-14$ Although most patients will experience resolution of symptoms after vascular ring division, a small number will require reoperation for persistent respiratory and esophageal symptoms. The most common procedure performed during reintervention surgery was aortopexy for tracheal compression followed by division of residual band tissue. These findings underscore the importance of complete division of underlying bands and scar tissue at the time of ring division, as well as careful inspection to ensure no persistent compression of the trachea by the aorta. ${ }^{15}$ Adjunctive intraoperative bronchoscopy may be useful to evaluate efficacy of ring division in relief of tracheal compression, and may guide further intraoperative maneuvers (aortopexy, tracheopexy). ${ }^{16}$

A significant cause of reintervention for airway obstruction in patients following vascular ring division is compression by the aorta or diverticulum of Kommerell; thus, many centers advocate performing a diverticular resection for RAA and reimplanting the aberrant LSCA into the left common carotid artery. ${ }^{17-19}$ Proponents of diverticulum resection suggest this procedure removes any source for recurrent tracheal or esophageal compression and thus is more likely to result in complete freedom from reintervention. Most patients in our series with RAA and Kommerell diverticulum underwent ligament division alone or minimal manipulation of diverticulum with acceptable midterm clinical outcomes; only 2 patients underwent reintervention (1 diverticulopexy and 1 reimplantation of left subclavian) specifically for diverticulum manipulation at midterm follow-up. Optimal management of the diverticulum at the time of vascular ring division warrants further investigation. 
Symptom resolution was documented in $74 \%$ of patients presenting for clinical follow-up visits in the early postoperative period. This rate likely underestimates the true incidence of early symptom resolution, because asymptomatic patients may be less likely to return for evaluation; however, among those with available clinical follow-up beyond 6 months, nearly a quarter were symptomatic enough to warrant airway imaging, with most of those patients presenting evidence of airway abnormalities. Airway abnormalities in some patients may not be completely reversible by vascular ring division, and structural tracheal abnormalities at the level of the ring may persist despite division, necessitating further intervention, such as tracheopexy in appropriate patients. Previous studies have suggested that persistent respiratory symptoms may be attributable to underlying airway pathology. ${ }^{1,10}$ The rate of reintervention for ongoing airway compression may be further reduced by adjunctive intraoperative bronchoscopy and concomitant decisions regarding tracheal or aortopexy at the time of the vascular ring division. On the other hand, some investigators claim that persistent symptoms may be due to persistence of diverticular abnormalities in patients with RAA. Patients with DAA experienced similar rates of chronic symptoms as RAA, suggesting that the etiology of persistent symptoms is underlying airway abnormality rather than persistent compression.

Selection of approach for division of vascular ring has evolved over the study period. Patients undergoing VATS tended to be older and to weigh more. In addition, specific type of vascular ring determined approach, with patients with DAA more likely to undergo thoracotomy over VATS. Nevertheless, 4 patients in the series underwent division of DAA with patent left arch safely by VATS approach, whereas previous contraindication to VATS surgery has been presence of a patent arch. ${ }^{2,7}$ Although the field of exposure is greater with thoracotomy, visualization with the VATS approach is enhanced by high-resolution video, which may mitigate risk of injury to adjacent structures. The risk of pneumothorax is related to injury sustained during retraction of lung parenchyma or air entrained during chest tube removal with the VATS approach. Postoperative chest tubes are frequently not required for VATS, and improvements in design of retractors have minimized risk of parenchymal injury.

Among patients with RAA with LSCA/LL, OR duration and hospital LOS was shorter among those who underwent VATS compared with thoracotomy. Previous studies have shown similar postoperative hospital LOS and similar or longer operation times in vascular ring division and ligation of PDA by using the VATS approach compared with thoracotomy, although neither study limited findings to one vascular ring anatomical configuration. ${ }^{2,6,20}$ The longer time taken for dissection of structures and division may be counterbalanced by the shorter time taken to obtain exposure (skin incision, port or retractor placement) for VATS compared with thoracotomy, Shorter hospital LOS may be explained by a smaller percentage of VATS patients requiring mechanical ventilation or placement of chest tubes postoperatively, less postoperative pain, and reduced blood loss compared with thoracotomy. ${ }^{21,22}$ Although data on cost were not collected in this study, shorter LOS would likely have favorable impact on financial metrics. We found no significant difference in rate of complications or reinterventions in those patients undergoing VATS compared with thoracotomy among patients with RAA with LSCA/LL. Our findings are consistent with those previously reported when comparing rate of complications between VATS and thoracotomy for PDA ligation. ${ }^{20}$

Patients who underwent conversion from VATS approach to thoracotomy during vascular ring division were not at increased risk of complications as a result of conversion. The rate of reintervention surgery and recurrent symptoms was similar to the overall cohort. The reasons for converting to thoracotomy, similar to those described in previous series, included discovery of a patent DAA, concern for bleeding, and inability to attain adequate exposure. , $^{2,6,11}$ Patients who converted did not experience significant complications, suggesting that the strategy of VATS as initial approach followed by conversion to thoracotomy in appropriate cases is safe and reasonable. Importantly, the skin incisions for VATS surgery can be subsequently used as a part of the thoracotomy skin incision in case conversion becomes necessary.

This is a retrospective study and subject to several important limitations. Although we were able to follow nearly two-thirds of our cohort beyond 6 months, the overall long-term follow-up length was suboptimal, and followup from Boston Children's Hospital patient medical records may be incomplete if patients underwent further procedures at other institutions. We collected operative characteristics from several decades, a study period that spanned potential change in practice. Because the number of patients experiencing complications or reintervention was small, the lack of statistical significance when testing for differences may have been due to lack of power. Although attempts were made to adjust for covariates, differences in age and diagnosis between groups are confounding variables that can be eliminated only by prospective randomized clinical trial design. Because preoperative and postoperative symptoms were extrapolated from medical records, they are subject to interpretation bias. Although included adjustment for patient age and weight in our analysis, these patient factors may still confound our results. Although the difference was not statistically significant, patients who underwent repair of RAA with LSCA/LL by VATS were generally older and weighed more compared with those who 
underwent thoracotomy, characteristics that may affect OR duration and hospital LOS. Furthermore, surgeon preference for thoracotomy or VATS may introduce selection bias into the study.

In conclusion, we found that thoracoscopic division of complete vascular rings in children and young adults offers a safe and effective approach to management of vascular rings. Among patients with RAA with LSCA/LL, thoracoscopic approach was found to have shorter operation time and hospital stays, and similarly low rates of complication and reintervention. Randomized prospective trials with long-term clinical follow-up are necessary to confirm these findings and determine impact of diverticular resection and reimplantation on outcomes. Future investigations could include analysis of predictors of symptom recurrence and need for reintervention in patients with vascular rings.

\section{Webcast}

You can watch a Webcast of this AATS meeting presentation by going to: http://webcast.aats.org/2016/Video/ Tuesday/05-17-16_Ballroom_III_1630_Herrin-800.mp4.

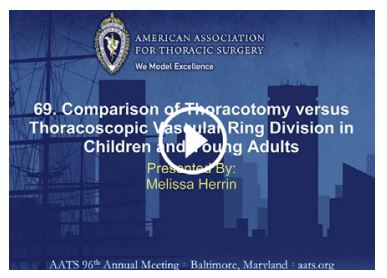

\section{Conflict of Interest Statement}

Authors have nothing to disclose with regard to commercial support.

\section{References}

1. Humphrey C, Duncan K, Fletcher S. Decade of experience with vascular rings at a single institution. Pediatrics. 2006;117:e903-8.

2. Kogon BE, Forbess JM, Wulkan ML, Kirshbom PM, Kanter KR. Video-assisted thoracoscopic surgery: is it a superior technique for the division of vascular rings in children? Congenit Heart Dis. 2007;2:130-3.

3. Shah RK, Mora BN, Bacha E, Sena LM, Buonomo C, Del Nido P, et al. The presentation and management of vascular rings: an otolaryngology perspective. Int J Pediatr Otorhinolaryngol. 2007;71:57-62.

4. Woods RK, Sharp RJ, Holcomb GW III, Snyder CL, Lofland GK, Ashcraft KW, et al. Vascular anomalies and tracheoesophageal compression: a single institution's 25-year experience. Ann Thorac Surg. 2001;72:434-8; discussion 438-39.

5. Mihaljevic T, Cannon JW, del Nido PJ. Robotically assisted division of a vascular ring in children. J Thorac Cardiovasc Surg. 2003;125:1163-4.

6. Burke RP, Rosenfeld HM, Wernovsky G, Jonas RA. Video-assisted thoracoscopic vascular ring division in infants and children. J Am Coll Cardiol. 1995; 25:943-7.

7. Burke RP, Wernovsky G, van der Velde M, Hansen D, Castaneda AR. Video-assisted thoracoscopic surgery for congenital heart disease. J Thorac Cardiovasc Surg. 1995;109:499-507; discussion 508.

8. Naimo PS, Sawan E, Donald JS, Sawan E, d'Udekem Y, Brizard CP, et al. Longterm outcomes of a complete vascular ring division in children: 36-year experience from a single institution. Presented at: Society of Thoracic Surgeons Annual Meeting; January 23-27, 2016; Phoenix, AZ.

9. Harris EK, Albert A. Survivorship Analysis for Clinical Studies. New York: M. Dekker; 1991.
10. Alsenaidi K, Gurofsky R, Karamlou T, Williams WG, McCrindle BW. Management and outcomes of double aortic arch in 81 patients. Pediatrics. 2006;118 e1336-41

11. Al-Bassam A, Saquib Mallick M, Al-Qahtani A, Al-Tokhais T, Gado A, AlBoukai A, et al. Thoracoscopic division of vascular rings in infants and children. J Pediatr Surg. 2007;42:1357-61.

12. Naimo PS, Fricke TA, Donald JS, Sawan E, d'Udekem Y, Brizard CP, et al. Long term outcomes of complete vascular ring division in children: a 36-year experience from a single institution. Interact Cardiovasc Thorac Surg. October 20 2016 [Epub ahead of print].

13. Backer CL, Mavroudis C, Rigsby CK, Holinger LD. Trends in vascular ring surgery. J Thorac Cardiovasc Surg. 2005;129:1339-47.

14. Backer CL, Monge MC, Russell HM, Popescu AR, Rastatter JC, Costello JM Reoperation after vascular ring repair. Semin Thorac Cardiovasc Surg Pediatr Card Surg Annu. 2014;17:48-55.

15. Emani S. Patent ductus arteriosus, coarctation of the aorta, and vascular rings. In: Sellke FM, Del Nido P, Swanson SJ, eds. Surgery of the Chest. Philadelphia, PA Elsevier; 2015:2026-42.

16. Oh J, Kim JW, Shin WJ, Gwak M, Park PH. Usefulness of intraoperative bronchoscopy during surgical repair of a congenital cardiac anomaly with possible airway obstruction: three cases report. Korean J Anesthesiol. 2016;69:71-5.

17. Backer CL, Hillman N, Mavroudis C, Holinger LD. Resection of Kommerell's diverticulum and left subclavian artery transfer for recurrent symptoms after vascular ring division. Eur J Cardiothorac Surg. 2002;22:64-9.

18. Luciano D, Mitchell J, Fraisse A, Lepidi H, Kreitmann B, Ovaert C. Kommerell diverticulum should be removed in children with vascular ring and aberrant left subclavian artery. Ann Thorac Surg. 2015;100:2293-7.

19. Backer CL, Russell HM, Wurlitzer KC, Rastatter JC, Rigsby CK. Primary resection of Kommerell diverticulum and left subclavian artery transfer. Ann Thorac Surg. 2012;94:1612-7.

20. Le Bret E, Papadatos S, Folliguet T, Carbognani D, Pétrie J, Aggoun Y, et al. Interruption of patent ductus arteriosus in children: robotically assisted versus videothoracoscopic surgery. J Thorac Cardiovasc Sur. 2002;123:973-6.

21. Liu CH, Li ZD, Bai CQ, Wang L, Shi XF, Song Y. Video-assisted thoracoscopic surgery and thoracotomy during lobectomy for clinical stage I non-small-cell lung cancer have equivalent oncological outcomes: a single-center experience of 212 consecutive resections. Oncol Lett. 2015;9:1364-72.

22. Dingemann C, Ure B, Dingemann J. Thoracoscopic procedures in pediatric surgery: what is the evidence? Eur J Pediatr Surg. 2014;24:14-9.

Key Words: vascular ring, video-assisted thoracoscopic surgery, right aortic arch with aberrant left subclavian

\section{Discussion}

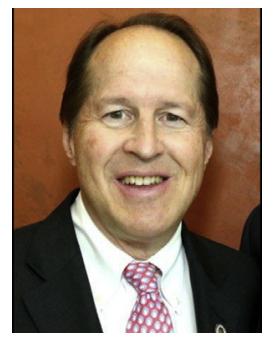

Dr C. Backer (Chicago, Ill). I would like to congratulate Ms Herrin and her colleagues at Boston Children's Hospital on reporting an update on their series of vascular ring patients treated with VATS. I was actually the discussant when Dr Redmond Burke presented this at The American Association for Thoracic Surgery in New York City in 1994.

At that time, Redmond reported 8 patients undergoing a vascular ring division using VATS. My conclusion at the time of the discussion was that "this technique may have some promise for selected pediatric patients." That conclusion still appears to be correct with an emphasis on the word "selected."

The strategy for the care of patients with vascular rings at Boston Children's Hospital appears to have evolved to one where the patients are stratified to VATS if they have an 
atretic arch or a ligamentum that requires division. This accounted for 111 out of 115 of your VATS patients. In contrast, only 4 patients with a patent vascular ring underwent a VATS procedure. I'm certain that some of this hesitation relates to the risk of intraoperative bleeding.

My first question to you is: with a very small number of patients undergoing division of a truly patent arch (it is less than $5 \%$ of your series), do you still intend to recommend VATS procedures in patients with a patent vascular ring, a patent arch?

Ms Herrin. Thank you, Dr Backer. I think we would acknowledge that in our series a small number underwent VATS division of patent arches, so what we would say is that it really is dependent upon the comfort level and experience of the surgeon. Certainly, even within our own group, some surgeons will do VATS divisions of patent double aortic arches, whereas some prefer thoracotomy or a combination of each.

And so while we believe it's a reasonable approach, it's entirely dependent on, as we said, sort of the comfort and experience of the surgeon.

Dr Backer. Can I take the prerogative of polling the room? How many people here do VATS procedures for patent arches and vascular rings?

(A show of hands.)

Dr Backer. I only see 1 or 2 hands raised! My next question relates to the postoperative length of stay. This is the only factor that was significantly improved by the VATS technique. There are 2 important factors to consider here: the age of the patients and the anatomy. First, there was a significant age difference between the 2 populations; the VATS group having a mean age of 2.7 years, the thoracotomy group having a mean age of only 0.9 years.

Second, the anatomy in the VATS group was mostly ligamentum divisions. Just out of curiosity, I looked at our own series from Ann \& Robert H. Lurie Children's Hospital of Chicago. In the past 15 years, we had 33 patients with a right aortic arch who just underwent ligamentum ligation and division. We use a muscle-sparing technique, limited use of chest tubes, and when we do use "chest tubes," we use small silastic Blake drains.

Our median length of stay in that select group is 2 days, only half a day longer than your VATS group, but it is 1 and a half days shorter than your thoracotomy group.

So, there are these 2 factors; the patient anatomy (which is simpler in the VATS group), and the substantial age difference. These 2 factors I believe help explain the difference in length of stay.

So do you have information if you compared the length of stay of the corresponding thoracotomy patients who only had a ligamentum or atretic arch division versus those that had a patent arch, and can you do that with age match controls? I'm maybe asking too much.
Ms Herrin. Thank you. Yes. With regard to chest tube placement, none of the VATS patients get chest tubes postoperatively; rather, if they do, they're removed the next day.

Within the thoracotomy patients, they tend to get chest tubes, which, as you're right, would prolong hospital length of stay. Although, in some they can be removed the next day.

With regard to excluding the patent double aortic arches from the thoracotomy group, we did run that analysis, and it did not significantly change the median hospital length of stay.

We also tried to adjust somewhat for age by running a multivariate logistic regression in our analysis, but you did point out that the number of patients in the VATS group with patent double aortic arches was very low. And when we ran that logistic regression, it did include the patent double aortic arches in the thoracotomy group, so it would be absolutely worth it to go back and do age match comparisons or regression analysis to compare.

Dr Backer. My next question relates to the cost of the procedure. With the VATS approach, you need to use disposable equipment, which has a certain cost. The cost for the patients undergoing a thoracotomy is typically only the reusable vascular clamps and the cost of the suture.

I actually asked Redmond the same question 20 years ago. I didn't really get an answer, so maybe you can tell me. What's the additional cost of the supplies in the operating room for the disposables?

Ms Herrin. So I'd like to first say that currently no disposable materials are used any longer. The instruments are sterilized and reused with the one exception of the titanium clips that are disposable. And I'm sorry to say, I don't have a cost analysis comparison to report today, but if we believe that the difference is in hospital length of stay, that our analysis has showed that there really is a difference in hospital length of stay, we would expect the cost savings within the VATS group, if they actually stayed a couple days shorter, it would be a pretty significant cost reduction.

Dr Backer. My final question and comment relates to your last slide when you talked about left subclavian artery reimplantation. We have found that with the use of advanced imaging, a Kommerell diverticulum or a circumflex aorta can be the main contributor to the patient's symptoms rather than just the ligamentum alone.

In our right aortic arch population in the past 15 years, out of 97 patients, 35 have undergone a Kommerell diverticulum resection and left subclavian artery reimplantation. Now, some of that may be skewed because these patients are specifically referred to us with that diagnosis.

That being said, what is your philosophy regarding the patients with Kommerell diverticulum or a circumflex aorta? We have a philosophy that a more comprehensive initial operation is better than simple ligamentum division, 
waiting to see what happens, and then coming back for a reoperation if symptoms recur.

Please give me your thoughts on that, and if you want to defer to Ram, that's fine, too. I know you're a medical student. Anyway, great presentation. Thank you.

Ms Herrin. Thank you, Dr Backer, and we appreciate your experience as well.

I think that our position would be that VATS is a reasonable first approach for right aortic arch with aberrant left subclavian, left ligamentum, as long as we do not note an aneurysmal Kommerell diverticulum for an initial first operation.

So if it's mild, ligamentum division we believe would be a reasonable first step.

If there is evidence of aneurysm, then we absolutely agree that reimplantation and diverticular resection would be an appropriate step to take.

The one benefit of doing VATS first is that it makes for a less difficult redo thoracotomy if needed, which we think is notable. I can defer to Dr Emani if he has anything else to say.

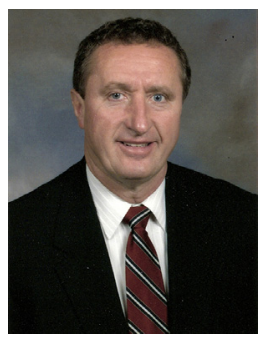

Dr J. Brown (Indianapolis, Ind). Was there an incidence of recurrent nerve injury in your series?

Ms Herrin. I'm sorry?

Dr Brown. What is your incidence of recurrent laryngeal nerve? Was the incidence different between the thoracotomy and the VATS?

Ms Herrin. Seven patients had recurrent laryngeal nerve paresis or damage. There was no difference between the 2 groups. Was that your question?

Dr Brown. Yes, that is the question. So 3 and 3 in each group, or 3 and 4? Seven sounds high, and that's why I asked. The VATS instrumentation looks a little, I hate to use the word "crude," but it's big, particularly for smaller children.

This incidence is high in our experience. I don't know what the reported incidence is in other series. Maybe it's not, but it would be in our institution.
Dr Emani. We noted obviously vocal cord paresis in 7 patients. Sometimes it can be hard to tell how much of it is truly nerve transection versus stretch related.

The one advantage of the VATS I think is actually superior visualization and magnification of the area. So I've found that you can actually get the camera underneath and get an angle to look. Really the problem is often behind the ligamentum, and you can actually see the course of the nerve as it's heading underneath and can push that to the side. So I found that to be an advantage of the approach.

But, yes, it was 3 and 4 when I recall when we looked at the split.

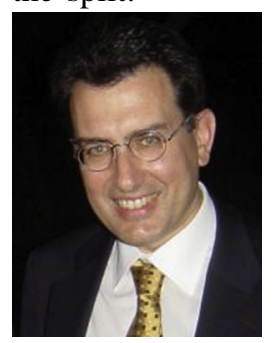

Dr G. Sarris (Athens, Greece). My question pertains to the subpopulation of patients who have the aberrant left subclavian and right arch. Embryologically these patients always have an atretic segment of the left arch.

So does the operation which you perform, either open or by VATS, simply divide the ligamentum, or does it also address the atretic component of the left arch?

Ms Herrin. I'm sorry. I didn't fully hear you.

Dr Sarris. In this lesion, the vascular ring includes the atretic component of the left arch and the ligamentum. The question is, regarding the operation which is performed, either open or by VATS, does it simply divide the ligamentum, or does it also include division of the atretic component of the left arch?

Ms Herrin. I'll let Dr Emani answer, but I believe that it was both, addressed both.

Dr Emani. Yes. The operation for the double aortic arch with the atretic segment involves division of the ligamentum plus the division of the atretic segment, so, yes, for all cases.

And that's why for the patent double arches, frequently it's done open, whereas for the atretic segment, you would typically do it by VATS. 